\title{
Alterações da qualidade tecnológica de marcas comerciais de feijão dos grupos cores e preto
}

\author{
Changes in technological quality of black and carioca beans \\ commercial genothypes
}

\author{
Lucinéia de Oliveira Grobs Zimmermann ${ }^{1}$; Silvia Renata Machado Coelho ${ }^{2 *}$; \\ Divair Christ ${ }^{3}$; Lúcia Helena Pereira Nóbrega ${ }^{3}$
}

\begin{abstract}
Resumo
O consumo de feijão comum (Phaseolus vulgaris L.) pode ser prejudicado por um defeito textural conhecido como hard-to-cook (HTC), o qual aumenta o tempo de cocção do grão, diminuindo sua qualidade. O objetivo deste trabalho foi avaliar a qualidade tecnológica de marcas comerciais de feijão preto e carioca, relacionando ao aparecimento do defeito HTC. Análises de absorção de água pelos grãos foram realizadas sob dois métodos de maceração, como também da absorbância do caldo obtido durante a maceração, além da análise de $\mathrm{pH}$ dos grãos inteiros. Diferenças na absorção de água nos grãos das marcas analisadas foram observadas e a maceração por uma hora com adição de água em ebulição correspondem à absorção de água de cerca de oito horas em temperatura ambiente. Houve diferenças na absorbância do caldo de maceração, indicando maior perda de solúveis em marcas que também apresentaram redução de $\mathrm{pH}$, o que pode indicar início da instalação do defeito HTC nos grãos. Os grãos macerados com adição de água em ebulição apresentaram grande perda de solúveis no caldo em comparação à maceração em temperatura ambiente.
\end{abstract}

Palavras-chave: Phaseolus vulgaris L, qualidade de cozimento, maceração

\begin{abstract}
Common bean (Phaseolus vulgaris L.) consumption may be affected by a textural defect named hardto-cook (HTC), that increases grain cooking time of the grain, reducing its quality. The objective of this work was to evaluate the quality of black and carioca beans commercial genothypes, relating with the appearance of HTC defect. Water absorption analyses had been carried through for grains in two soaking methods and absorvance of broth gotten during the soaking, beyond $\mathrm{pH}$ analysis of the grains. Differences were observed in grain water absorption of analyzed commercial genotyphes and the soaking for one hour with water in boiling point corresponds to a water absorption at about eight hours in ambient temperature. There were differences in absorvance of soaking broth, indicating bigger loss of soluble in commercial genotypes that had also presented $\mathrm{pH}$ reduction, what may indicate the beginning of grains installation HTC. Grains soaked with water in boiling point presented a great loss of soluble in broth in comparison with soaking in ambient temperature.
\end{abstract}

Key words: Phaseolus vulgaris L, cooking quality, soaking

1 Biológa - Laboratório de Análises de Farinha e Grão de Trigo da FAG - Cascavel- PR

2 Engenheira Agrônoma, Doutora, Professor Adjunto do Curso de Graduação e Pós-Graduação em Engenharia Agrícola - CCET - UNIOESTE- Cascavel. E-mail: srmcoelho@unioeste.br.

3 Curso de Graduação e Pós-Graduação em Engenharia Agrícola - CCET - UNIOESTE- Cascavel.

* Autor para correspondência 


\section{Introdução}

Grãos de feijão comum representam importante fonte protéica na dieta humana nos países em desenvolvimento, das regiões tropicais e subtropicais do planeta, particularmente nas Américas e no leste e sul da África (YOKOYAMA, 2006). A área cultivada dessa leguminosa no Brasil apresenta crescimento nos últimos anos agrícolas e, na safra 2006/2007, alcançou 4,18 milhões de hectares. As maiores participações em área, e na produção, ocorreram no Paraná e Minas Gerais com 563 e 623 mil hectares, respectivamente. Observa-se, ainda, enormes diferenciais de produtividade no país, uma vez que, enquanto no Nordeste colhe-se abaixo de $400 \mathrm{~kg} \mathrm{ha}^{-1}$, nas lavouras do Centro-Oeste obtêm-se médias maiores que $1.500 \mathrm{~kg} \mathrm{ha}^{-1}$, sendo a média nacional em 2007 de $856 \mathrm{~kg} \mathrm{ha}^{-1}$ (INSTITUTO BRASILEIRO DE GEOGRAFIA E ESTATÍSTICA - IBGE, 2007).

O armazenamento de sementes de feijão é feito, geralmente, em condições ambientais não controladas, com alta temperatura e umidade relativa (SANTOS; MENEZES; VILLELA, 2005). Condições controladas de armazenamento são essenciais para a preservação da qualidade do grão. Assim, grãos armazenados em condições de alta temperatura e umidade relativa tornamse endurecidos e resistentes ao cozimento devido, principalmente, a um defeito denominado difícil de cozinhar ou "hard-to-cook" (HTC), quando os grãos são capazes de absorver água, mas os cotilédones não amaciam durante o cozimento ocasionando aumento do tempo de cozimento para o amaciamento dos cotilédones, menor aceitação pelo consumidor, diminuição do valor nutritivo pela perda de vitaminas, alterações de sabor, perda de consistência do caldo e modificações da cor dos grãos (REYES-MORENO; PAREDES-LOPES, 1993; LIU, 1995; BRAGANTINI, 2005).

Segundo Bassinello et al. (2005), as principais características físicas e químicas relacionadas à avaliação da qualidade tecnológica dos grãos são: absorção de água antes e após o cozimento, tempo de cozimento, percentagem de sólidos solúveis no caldo, cor do tegumento e do caldo, teor de fibra dietética, minerais, proteínas e vitaminas. Além disso, a medição da cor dos caldos de maceração em feijão é um bom indicador da perda ou lixiviação de solúveis, a qual pode ser relacionada ao envelhecimento dos grãos. Maurer et al. (2004), estudando a reflectância do caldo por meio de infra vermelho, observaram que grãos de feijão com defeito HTC apresentaram maiores perdas de solúveis no caldo de maceração que os feijões controle.

No processamento doméstico do feijão-comum, a maceração dos grãos crus em água a diferentes temperaturas por período variável é prática corrente. Pesquisas com feijão têm sido realizadas sobre o efeito da maceração em seu valor nutritivo, hábitos preferenciais dos consumidores e textura dos grãos, e têm demonstrado diminuição de oligossacarídeos e fatores antinutricionais com esta prática, além da diminuição do tempo de cozimento pela melhoria da textura (CASTELLANOS; MALDONADO; JIMÉNEZ, 1997; ABU-GHANNAM， 1998; OLIVEIRA et al., 2001).

O objetivo deste trabalho foi avaliar a qualidade tecnológica das marcas comerciais de grãos de feijão, grupo preto e cores (variedade carioca), disponíveis em supermercados, pela análise de variáveis de absorção de água, cor do caldo e pH do tecido, relacionando a perda de qualidade à instalação do defeito HTC, além de avaliar a influência da temperatura de maceração na absorção de água e perda de solúveis.

\section{Material e métodos}

O experimento foi desenvolvido no período de abril a junho de 2006, no Laboratório de Bioquímica da Universidade Paranaense - UNIPAR, na cidade de Cascavel/PR, utilizando-se grãos de feijão do grupo cores, variedade carioca e grupo preto da safra 2005/2006, sendo seis marcas comerciais para 
cada grupo, adquiridas no comércio da cidade de Cascavel/PR. Amostras de cada marca comercial, armazenadas sob refrigeração a $5^{\circ} \mathrm{C}$ durante $\mathrm{o}$ período do experimento, foram submetidas a análises físico-químicas, realizadas em triplicata.

\section{Teste de absorção de água}

Cinquenta gramas dos grãos inteiros foram pesados e acondicionados em embalagens de policloreto de vinila (PVC) trançado e novamente pesados. O conjunto grãos e embalagem de PVC foi inserido em recipientes contendo $200 \mathrm{~mL}$ de água destilada à temperatura ambiente, e macerados por um período de $14 \mathrm{~h}$. A cada hora, as embalagens com os feijões eram retiradas da água e deixadas em repouso por dois minutos em papel absorvente para posterior pesagem, conforme método adaptado de Abreu et al. (2002).

Para o teste de absorção de água em ebulição nos grãos utilizou-se, para a maceração, água a $100^{\circ} \mathrm{C}$. Para tanto, adotou-se o mesmo procedimento para acondicionamento dos grãos, os quais foram colocados em recipiente com $200 \mathrm{~mL}$ de água em ebulição. Após uma hora de maceração, as amostras foram retiradas da água e antes da pesagem, foi realizado repouso por dois minutos em papel absorvente, para posterior pesagem de cada amostra.

\section{Análise espectrofotométrica do caldo de maceração}

Paralelamente ao teste de absorção de água foi realizada a leitura espectrofotométrica do caldo de maceração, utilizando-se espectrofotômetroFEMTO modelo 700. Dois mililitros da água de maceração dos grãos foi retirada a cada hora, durante o teste de absorção de água em todas as amostras analisadas. Realizou-se, então, a leitura de absorbância da água de maceração em comprimento de onda de $352 \mathrm{~nm}$ para o feijão carioca e $570 \mathrm{~nm}$ para o feijão preto. Os valores de comprimento de onda, utilizados na leitura de absorbância e específicos para feijão preto e carioca, foram selecionados por meio de varredura do espectro de absorção, utilizando-se o comprimento de onda do maior valor de absorbância obtido, uma vez que a água de maceração de cada tipo de grão apresentou cor distinta.

Para os grãos macerados com adição de água em ebulição, a leitura foi realizada após uma hora, para todas as amostras das marcas avaliadas.

\section{Determinação do $\mathrm{pH}$ dos grãos}

Para o preparo da amostra, os grãos inteiros foram triturados em liquidificador e para a determinação do $\mathrm{pH}$, utilizou-se $10 \mathrm{~g}$ de amostra diluídas em $50 \mathrm{~mL}$ de água destilada. Esta mistura foi homogeneizada em agitador magnético por cinco minutos e deixada em repouso por 10 minutos para a sedimentação do material sólido. Após este período, o pH foi medido diretamente no sobrenadante (COELHO, 2004).

\section{Análise estatística}

Para os testes de absorção de água e análise espectrofotométrica do caldo de maceração, utilizouse delineamento inteiramente casualizado (DIC), em esquema de parcelas subdivididas, e as marcas comerciais de feijão dos grupos cores ou preto como parcelas e os tempos de maceração como subparcelas, com três repetições. Os resultados obtidos foram submetidos à análise de variância (ANOVA), teste $\mathrm{F}$ de Snedecor e teste de comparação de médias (Teste de Scott-Knott) e realizada a análise de regressão polinomial e teste " $t$ " para significância de coeficiente de determinação $\left(\mathrm{R}^{2}\right)$. O nível de significância considerado foi igual ou menor que 5\%. As análises de variância e regressão polinomial foram realizadas pelo programa estatístico ESTAT - Sistema para Análises Estatísticas - V.2.0 (UNIVERSIDADE ESTADUAL PAULISTA-UNESP, 1991). Para a análise estatística do $\mathrm{pH}$ foi obtida a diferença mínima significativa (DMS) entre as médias de cada marca comercial pelo teste de Tukey. 


\section{Resultados e discussão}

Os resultados relativos à análise de variância da porcentagem de absorção de água do feijão de marcas comerciais do grupo cores, variedade carioca e grupo preto macerados por 13 horas em temperatura ambiente demonstram que houve interação entre o tempo de hidratação e as marcas avaliadas. Nas Tabelas 1 e 2 são apresentados os valores da porcentagem de absorção de água dos grãos de feijão de seis marcas do grupo cores, variedade carioca e do grupo preto, obtidas no comércio da cidade de Cascavel - PR, macerados por até 13 horas em água à temperatura ambiente.

Para os grãos de feijão do grupo carioca (Tabela 1), a marca $F$ apresentou maior porcentagem de absorção de água em todos os tempos analisados, sendo igual à marca $\mathrm{C}$ a partir da quarta hora de maceração. A marca B foi a que apresentou menor porcentagem de absorção de água em todos os tempos, e a marca D, a partir da quinta hora de maceração foi igualada à $\mathrm{B}$, as quais apresentaram, ao final das $13 \mathrm{~h}$ de maceração, absorção de água inferior a $90 \%$.

Tabela 1. Porcentagem de absorção de água em seis marcas comerciais de grãos de feijão do grupo cores, variedade carioca, disponíveis no comércio de Cascavel - PR, macerados por até $13 \mathrm{~h}$ em água à temperatura ambiente

\begin{tabular}{|c|c|c|c|c|c|c|c|c|c|c|c|c|c|c|}
\hline \multirow[b]{2}{*}{$\mathrm{M}$} & \multicolumn{14}{|c|}{ Tempo de maceração (horas) } \\
\hline & 1 & 2 & 3 & 4 & 5 & 6 & 7 & 8 & 9 & 10 & 11 & 12 & 13 & $\mathrm{x}$ \\
\hline A & $40,6^{\mathrm{gC}}$ & $57,5^{\mathrm{fB}}$ & $68,9^{\mathrm{eB}}$ & $75,2^{\mathrm{dC}}$ & $80,0^{\mathrm{cB}}$ & $82,7^{\mathrm{cB}}$ & $85,0^{\mathrm{bB}}$ & $86,6^{\mathrm{bB}}$ & $87,9^{\mathrm{bB}}$ & $89,8^{\mathrm{aB}}$ & $90,9^{\mathrm{aB}}$ & $91,5^{\mathrm{aB}}$ & $92,1^{\mathrm{aB}}$ & 79,1 \\
\hline B & $24,3^{\mathrm{hD}}$ & $41,5^{\mathrm{gC}}$ & $57,2^{\mathrm{fC}}$ & $66,1^{\mathrm{eD}}$ & $73,4^{\mathrm{dC}}$ & $77,6^{\mathrm{cC}}$ & $80,4^{\mathrm{bC}}$ & $82,6^{\mathrm{bC}}$ & $84,3^{\mathrm{bC}}$ & $86,6^{\mathrm{aC}}$ & $88,0^{\mathrm{aC}}$ & $88,6^{\mathrm{aC}}$ & $89,8^{\mathrm{aC}}$ & 72,3 \\
\hline $\mathrm{C}$ & $38,1^{\mathrm{hC}}$ & $56,4^{\mathrm{gB}}$ & $70,3^{\mathrm{fB}}$ & $78,2^{\mathrm{eB}}$ & $83,4^{\mathrm{dA}}$ & $86,7^{\mathrm{cA}}$ & $89,1^{\mathrm{bA}}$ & $90,9^{\mathrm{bA}}$ & $91,9^{\mathrm{bA}}$ & $93,8^{\mathrm{aA}}$ & $95,0^{\mathrm{aA}}$ & $95,4^{\mathrm{aA}}$ & $96,4^{\mathrm{aA}}$ & 82,0 \\
\hline D & $42,4^{\mathrm{gB}}$ & $59,5^{\mathrm{fB}}$ & $73,8^{\mathrm{eB}}$ & $77,1^{\mathrm{dC}}$ & $78,5^{\mathrm{cC}}$ & $79,8^{\mathrm{bC}}$ & $80,7^{\mathrm{bC}}$ & $82,1^{\mathrm{bC}}$ & $82,8^{\mathrm{bC}}$ & $84,2^{\mathrm{aC}}$ & $85,4^{\mathrm{aC}}$ & $85,8^{\mathrm{aC}}$ & $86,2^{\mathrm{aD}}$ & 76,8 \\
\hline $\mathrm{E}$ & $44,5^{\mathrm{gB}}$ & $59,6^{\mathrm{fB}}$ & $71,7^{\mathrm{eB}}$ & $76,0^{\mathrm{dC}}$ & $80,6^{\mathrm{cB}}$ & $82,8^{\mathrm{cB}}$ & $84,9^{\text {bВ }}$ & $86,4^{\text {bB }}$ & $87,9^{\mathrm{bB}}$ & $89,7^{\mathrm{aB}}$ & $91,3^{\mathrm{aB}}$ & $91,7^{\mathrm{aB}}$ & $92,3^{\mathrm{aB}}$ & 80,0 \\
\hline $\mathrm{F}$ & $51,4^{\mathrm{gA}}$ & $66,8^{\mathrm{fA}}$ & $77,9^{\mathrm{eA}}$ & $81,8^{\mathrm{dA}}$ & $85,7^{\mathrm{cA}}$ & $87,4^{\mathrm{bA}}$ & $89,2^{\mathrm{bA}}$ & $90,6^{\mathrm{bA}}$ & $91,5^{\mathrm{bA}}$ & $92,8^{\mathrm{aA}}$ & $93,9^{\mathrm{aA}}$ & $94,3^{\mathrm{aA}}$ & $95,2^{\mathrm{aA}}$ & 84,5 \\
\hline $\mathrm{x}$ & 40,2 & 56,9 & 70,8 & 75,2 & 80,0 & 82,9 & 84,9 & 86,6 & 87,7 & 89,5 & 90,7 & 91,2 & 92,0 & \\
\hline
\end{tabular}

Letras maiúsculas iguais na mesma coluna e minúsculas na mesma linha não diferem entre si em nível de 5\% de significância pelo teste de Scott-Knott

Já para o feijão do grupo preto (Tabela 2), as marcas $\mathrm{E}$ e $\mathrm{F}$ estatisticamente apresentaram maiores porcentagem na absorção de água em todos os tempos, com absorção de água igual às demais marcas após dez horas de maceração. A marca D apresentou, no início da maceração, baixa porcentagem de absorção de água, mas ao final do tempo de maceração todas as marcas analisadas apresentaram porcentagem de absorção de água acima de 90\%. Observou-se, ainda, que os valores iniciais de absorção de água do grupo preto foram inferiores aos valores obtidos para o feijão carioca. Porém, ao final da maceração, esses valores foram equivalentes para ambos grupos avaliados. 
Tabela 2. Porcentagem de absorção de água em seis marcas de grãos de feijão da variedade preto, disponíveis no comercio de Cascavel - PR, macerados por até $13 \mathrm{~h}$ em água à temperatura ambiente

\begin{tabular}{|c|c|c|c|c|c|c|c|c|c|c|c|c|c|c|}
\hline \multirow[b]{2}{*}{ M } & \multicolumn{14}{|c|}{ Tempo de maceração (horas) } \\
\hline & 1 & 2 & 3 & 4 & 5 & 6 & 7 & 8 & 9 & 10 & 11 & 12 & 13 & $\mathrm{x}$ \\
\hline A & $27,4^{\mathrm{gB}}$ & $40,8^{\mathrm{fB}}$ & $57,1^{\mathrm{eB}}$ & $67,7^{\mathrm{dB}}$ & $75,1^{\mathrm{cB}}$ & $80,0^{\mathrm{cB}}$ & $83,5^{\mathrm{bB}}$ & $85,7^{\mathrm{bB}}$ & $87,9^{\mathrm{bA}}$ & $90,1^{\text {aA }}$ & $91,4^{\mathrm{aA}}$ & $92,6^{\mathrm{aA}}$ & $93,5^{\mathrm{aA}}$ & 74,8 \\
\hline B & $26,7^{\mathrm{hB}}$ & $39,6^{\mathrm{gB}}$ & $51,7^{\mathrm{fB}}$ & $61,4^{\mathrm{eB}}$ & $68,9^{\mathrm{dB}}$ & $73,9^{\mathrm{cB}}$ & $78,5^{\mathrm{cB}}$ & $81,2^{\mathrm{bB}}$ & $84,3^{\text {bA }}$ & $87,1^{\text {aA }}$ & $88,4^{\mathrm{aA}}$ & $90,0^{\mathrm{aA}}$ & $90,7^{\mathrm{aA}}$ & 70,9 \\
\hline $\mathrm{C}$ & $26,4^{\mathrm{hB}}$ & $40,0^{\mathrm{gB}}$ & $53,7^{\mathrm{fB}}$ & $63,2^{\mathrm{eB}}$ & $69,6^{\mathrm{dB}}$ & $75,3^{\mathrm{cB}}$ & $79,9^{\mathrm{cB}}$ & $83,4^{\mathrm{bB}}$ & $86,1^{\mathrm{bA}}$ & $89,2^{\mathrm{bA}}$ & $92,0^{\mathrm{aA}}$ & $94,4^{\mathrm{aA}}$ & $95,2^{\mathrm{aA}}$ & 73,0 \\
\hline D & $18,9^{\mathrm{hC}}$ & $34,1^{\mathrm{gC}}$ & $51,0^{\mathrm{fB}}$ & $96,9^{\mathrm{eB}}$ & $71,7^{\mathrm{dB}}$ & $77,7^{\mathrm{cB}}$ & $81,3^{\mathrm{bB}}$ & $83,3^{\text {bB }}$ & $85,7^{\mathrm{bA}}$ & $87,1^{\text {aA }}$ & $89,0^{\mathrm{aA}}$ & $90,3^{\mathrm{aA}}$ & $90,8^{\mathrm{aA}}$ & 71,1 \\
\hline $\mathrm{E}$ & $33,3^{\mathrm{gA}}$ & $50,9^{\mathrm{fA}}$ & $66,3^{\mathrm{eA}}$ & $75,0^{\mathrm{dA}}$ & $80,1^{\mathrm{cA}}$ & $84,6^{\mathrm{cA}}$ & $86,9^{\mathrm{bA}}$ & $88,5^{\mathrm{bA}}$ & $89,8^{\mathrm{bA}}$ & $91,4^{\mathrm{aA}}$ & $93,0^{\mathrm{aA}}$ & $93,9^{\mathrm{aA}}$ & $93,9^{\mathrm{aA}}$ & 79,1 \\
\hline F & $37,6^{\mathrm{gA}}$ & $53,6^{\mathrm{fA}}$ & $67,4^{\mathrm{eA}}$ & $76,8^{\mathrm{dA}}$ & $82,8^{\mathrm{cA}}$ & $85,7^{\mathrm{cA}}$ & $88,5^{\mathrm{bA}}$ & $89,7^{\mathrm{bA}}$ & $91,6^{\mathrm{bA}}$ & $93,0^{\mathrm{aA}}$ & $94,4^{\mathrm{aA}}$ & $94,9^{\mathrm{aA}}$ & $96,5^{\mathrm{aA}}$ & 81,0 \\
\hline X & 28,4 & 43,2 & 57,9 & 67,8 & 74,7 & 79,5 & 83,1 & 85,3 & 87,6 & 89,6 & 91,4 & 92,7 & 93,4 & \\
\hline
\end{tabular}

Letras iguais minúsculas na mesma linha e maiúsculas na mesma coluna não diferem entre si ao nível de 5\% de significância pelo teste de Scott-Knott.

A absorção de água, em todas as marcas analisadas de ambos os grupos, aumentou com o tempo de maceração, não apresentado diferenças significativas a partir da décima primeira hora, indicando que os grãos atingiram a máxima absorção de água com o tempo de maceração avaliado.

Abu-Ghannam (1998) observou, analisando temperaturas de maceração para feijão vermelho, absorção de água máximo de $90 \%$ em todas as temperaturas avaliadas. Ressaltou ainda que a quantidade de água absorvida foi crítica para a determinação da qualidade de feijões prontos para o consumo. Conforme Ramos Júnior, Lemos e Silva (2005), geralmente, em grãos de feijão deixados em maceração na noite anterior ao preparo, por um período de aproximadamente $12 \mathrm{~h}$, observa-se completa embebição nas amostras.

Uma opção para avaliar a qualidade dos grãos de feijão é por meio da quantidade de água absorvida em um determinado tempo e baseia-se no princípio que quanto mais rápida a absorção de água, maior é a capacidade de cozimento e alguns estudos têm mostrado correlação positiva e alta entre a quantidade de água absorvida e a capacidade de cozimento (COSTA; RAMALHO; ABREU, 2001).
Observou-se, ainda, que todas as marcas do feijão, de ambos os grupos, apresentaram aumento significativo na absorção de água, no início da maceração (uma a cinco horas) e a partir dos dados de porcentagem de absorção foram construídas curvas para se verificar o comportamento do fenômeno. $\mathrm{Na}$ Tabela 3 são apresentadas as equações de regressão para cada marca das variedades do feijão carioca e preto e os coeficientes de determinação $\left(\mathrm{R}^{2}\right)$, obtidas a partir dos dados de porcentagem de absorção de água. Todas as equações testadas apresentaram melhor ajuste para equação logarítimica, indicando o mesmo comportamento em todas as variedades.

Os resultados relativos à análise de variância da absorção de luz em absorbância da água de maceração do feijão de marcas comerciais do grupo cores, variedade carioca e grupo preto macerados por $13 \mathrm{~h}$ em temperatura ambiente demonstram que houve interação entre o tempo de hidratação e as marcas avaliadas. Os resultados relativos a absorção de luz em absorbância dos solúveis presentes na água de maceração dos grãos de feijão de marcas comerciais do grupo cores, variedade carioca e grupo preto macerados por 13 horas em temperatura ambiente estão apresentados nas Tabelas 4 e 5. 
Tabela 3. Equações de tendência dos dados da porcentagem de absorção de água em grãos de feijão das variedades carioca e preto, macerados por até $13 \mathrm{~h}$ em água a temperatura ambiente

\begin{tabular}{|c|c|c|}
\hline \multirow[b]{2}{*}{ M } & \multicolumn{2}{|c|}{ Equações polinomiais para absorção de água } \\
\hline & Carioca & Preto \\
\hline A & $\hat{y}=31,103 \operatorname{Ln}(x)+16,938 R^{2}=0,92$ & $\hat{y}=35,389 \operatorname{Ln}(x)+5,1621 R^{2}=0,97$ \\
\hline B & $\hat{y}=34,043 \operatorname{Ln}(x)+5,3921 R^{2}=0,97$ & $\hat{y}=34,524 \operatorname{Ln}(x)+3,3117 R^{2}=0,99$ \\
\hline $\mathrm{C}$ & $\hat{y}=33,536 \operatorname{Ln}(x)+15,152 R^{2}=0,93$ & $\hat{y}=36,287 \operatorname{Ln}(x)+2,1501 R^{2}=0,99$ \\
\hline $\mathrm{D}$ & $\hat{y}=27,663 \operatorname{Ln}(x)+20,252 R^{2}=0,87$ & $\hat{y}=36,396 \operatorname{Ln}(x)-0,051 R^{2}=0,97$ \\
\hline $\mathrm{E}$ & $\hat{y}=30,192 \operatorname{Ln}(x)+19,321 R^{2}=0,90$ & $\hat{y}=33,778 \operatorname{Ln}(x)+11,97 R^{2}=0,94$ \\
\hline $\mathrm{F}$ & $\hat{y}=29,698 \operatorname{Ln}(x)+24,365 R^{2}=0,85$ & $\hat{y}=33,683 \operatorname{Ln}(x)+13,901 R^{2}=0,94$ \\
\hline
\end{tabular}

Tabela 4. Absorção de luz em absorbância medida a $352 \mathrm{~nm}$ do caldo de maceração em temperatura ambiente das seis marcas de feijão do grupo cores, variedade carioca

\begin{tabular}{llllllllllllllll}
\hline \multirow{2}{*}{$\mathrm{M}$} & \multicolumn{1}{c}{} & \multicolumn{10}{c}{ Absorbância a $352 \mathrm{~nm}$} \\
& 1 & 2 & 3 & 4 & 5 & 6 & 7 & 8 & 9 & 10 & 11 & 12 & 13 & $\mathrm{x}$ \\
\hline $\mathrm{A}$ & $0,32^{\mathrm{eA}}$ & $0,49^{\mathrm{eB}}$ & $0,63^{\mathrm{dB}}$ & $0,75^{\mathrm{cB}}$ & $0,86^{\mathrm{cB}}$ & $0,97^{\mathrm{bB}}$ & $1,03^{\mathrm{bB}}$ & $1,16^{\mathrm{bB}}$ & $1,21^{\mathrm{aB}}$ & $1,26^{\mathrm{aB}}$ & $1,33^{\mathrm{aB}}$ & $1,38^{\mathrm{aB}}$ & $1,42^{\mathrm{aB}}$ & 0,99 \\
$\mathrm{~B}$ & $0,18^{\mathrm{fA}}$ & $0,38^{\mathrm{eB}}$ & $0,55^{\mathrm{dB}}$ & $0,71^{\mathrm{cB}}$ & $0,87^{\mathrm{cB}}$ & $1,00^{\mathrm{bB}}$ & $1,08^{\mathrm{bB}}$ & $1,18^{\mathrm{bB}}$ & $1,26^{\mathrm{aB}}$ & $1,32^{\mathrm{aB}}$ & $1,39^{\mathrm{aB}}$ & $1,43^{\mathrm{aB}}$ & $1,47^{\mathrm{aB}}$ & 0,98 \\
$\mathrm{C}$ & $0,28^{\mathrm{gA}}$ & $0,47^{\mathrm{fB}}$ & $0,63^{\mathrm{eB}}$ & $0,76^{\mathrm{dB}}$ & $0,88^{\mathrm{dB}}$ & $1,00^{\mathrm{cB}}$ & $1,08^{\mathrm{cB}}$ & $1,19^{\mathrm{cB}}$ & $1,28^{\mathrm{bB}}$ & $1,36^{\mathrm{bB}}$ & $1,44^{\mathrm{aB}}$ & $1,49^{\mathrm{aB}}$ & $1,54^{\mathrm{aB}}$ & 1,03 \\
$\mathrm{D}$ & $0,32^{\mathrm{eA}}$ & $0,51^{\mathrm{dB}}$ & $0,66^{\mathrm{CB}}$ & $0,77^{\mathrm{CB}}$ & $0,87^{\mathrm{cB}}$ & $0,97^{\mathrm{bB}}$ & $1,03^{\mathrm{bB}}$ & $1,11^{\mathrm{bB}}$ & $1,19^{\mathrm{aB}}$ & $1,24^{\mathrm{aB}}$ & $1,31^{\mathrm{aB}}$ & $1,35^{\mathrm{aB}}$ & $1,38^{\mathrm{aB}}$ & 0,98 \\
$\mathrm{E}$ & $0,36^{\mathrm{fA}}$ & $0,54^{\mathrm{eB}}$ & $0,65^{\mathrm{eB}}$ & $0,76^{\mathrm{dB}}$ & $0,88^{\mathrm{cB}}$ & $0,99^{\mathrm{cB}}$ & $1,08^{\mathrm{bB}}$ & $1,17^{\mathrm{bB}}$ & $1,27^{\mathrm{bB}}$ & $1,36^{\mathrm{aB}}$ & $1,44^{\mathrm{aB}}$ & $1,51^{\mathrm{aB}}$ & $1,58^{\mathrm{aB}}$ & 1,04 \\
$\mathrm{~F}$ & $0,45^{\mathrm{gA}}$ & $0,73^{\mathrm{fA}}$ & $0,89^{\mathrm{eA}}$ & $1,04^{\mathrm{e}}$ & $1,20^{\mathrm{dA}}$ & $1,36^{\mathrm{cA}}$ & $1,45^{\mathrm{cA}}$ & $1,59^{\mathrm{bA}}$ & $1,69^{\mathrm{aA}}$ & $1,79^{\mathrm{aA}}$ & $1,83^{\mathrm{aA}}$ & $1,88^{\mathrm{aA}}$ & $1,93^{\mathrm{aA}}$ & 1,37 \\
\hline $\mathrm{X}$ & 0,32 & 0,52 & 0,67 & 0,80 & 0,93 & 1,05 & 1,13 & 1,24 & 1,32 & 1,39 & 1,46 & 1,51 & 1,55 & \\
\hline
\end{tabular}

Letras iguais minúsculas na mesma linha e maiúsculas na mesma coluna não diferem entre si em nível de 5\% de significância pelo teste de Scott-Knott.

Tabela 5. Absorção de luz em absorbância medida a $570 \mathrm{~nm}$ do caldo de maceração em temperatura ambiente das seis marcas (M) do grupo preto

\begin{tabular}{|c|c|c|c|c|c|c|c|c|c|c|c|c|c|c|}
\hline \multirow{2}{*}{ M } & \multicolumn{14}{|c|}{ Absorbância a 570 nm } \\
\hline & 1 & 2 & 3 & 4 & 5 & 6 & 7 & 8 & 9 & 10 & 11 & 12 & 13 & $\mathrm{x}$ \\
\hline A & $0,08^{\mathrm{dA}}$ & $0,15^{\mathrm{dA}}$ & $0,21^{\mathrm{dA}}$ & $0,27^{\mathrm{dA}}$ & $0,34^{\mathrm{cA}}$ & $0,43^{\mathrm{cB}}$ & $0,54^{\mathrm{cB}}$ & $0,67^{\mathrm{bB}}$ & $0,76^{\mathrm{bB}}$ & $0,85^{\mathrm{bC}}$ & $0,93^{\mathrm{aC}}$ & $1,03^{\mathrm{aC}}$ & $1,05^{\mathrm{aD}}$ & 0,56 \\
\hline B & $0,13^{\mathrm{jA}}$ & $0,24^{\mathrm{jA}}$ & $0,32^{\mathrm{iA}}$ & $0,45^{\mathrm{iA}}$ & $0,57^{\mathrm{hA}}$ & $0,73^{\mathrm{gA}}$ & $0,93^{\mathrm{fA}}$ & $1,10^{\mathrm{eA}}$ & $1,31^{\mathrm{dA}}$ & $1,48^{\mathrm{cA}}$ & $1,64^{\mathrm{bA}}$ & $1,80^{\mathrm{aA}}$ & $1,93^{\mathrm{aA}}$ & 0,97 \\
\hline $\mathrm{C}$ & $0,09^{\mathrm{fA}}$ & $0,17^{\mathrm{fA}}$ & $0,22^{\mathrm{fA}}$ & $0,31^{\mathrm{fA}}$ & $0,38^{\mathrm{eA}}$ & $0,47^{\mathrm{eB}}$ & $0,59^{\mathrm{dB}}$ & $0,69^{\mathrm{cB}}$ & $0,83^{\text {bB }}$ & $0,94^{\mathrm{bC}}$ & $1,05^{\mathrm{aC}}$ & $1,16^{\mathrm{aC}}$ & $1,24^{\mathrm{aC}}$ & 0,63 \\
\hline $\mathrm{D}$ & $0,06^{\mathrm{fA}}$ & $0,14^{\mathrm{fA}}$ & $0,19^{\mathrm{fA}}$ & $0,28^{\mathrm{fA}}$ & $0,36^{\mathrm{eA}}$ & $0,46^{\mathrm{eB}}$ & $0,61^{\mathrm{dB}}$ & $0,74^{\mathrm{cB}}$ & $0,88^{\mathrm{bB}}$ & $1,00^{\mathrm{bC}}$ & $1,09^{\mathrm{aC}}$ & $1,19^{\mathrm{aC}}$ & $1,27^{\mathrm{aC}}$ & 0,64 \\
\hline E & $0,14^{\mathrm{eA}}$ & $0,20^{\mathrm{eA}}$ & $0,26^{\mathrm{eA}}$ & $0,35^{\mathrm{dA}}$ & $0,43^{\mathrm{dA}}$ & $0,53^{\mathrm{dB}}$ & $0,64^{\mathrm{cB}}$ & $0,75^{\mathrm{cB}}$ & $0,85^{\mathrm{cB}}$ & $0,94^{\mathrm{bC}}$ & $1,00^{\mathrm{bC}}$ & $1,10^{\mathrm{aC}}$ & $1,16^{\mathrm{aC}}$ & 0,64 \\
\hline $\mathrm{F}$ & $0,14^{\mathrm{fA}}$ & $0,19^{\mathrm{fA}}$ & $0,25^{\mathrm{fA}}$ & $0,36^{\mathrm{fA}}$ & $0,46^{\mathrm{eA}}$ & $0,59^{\mathrm{eB}}$ & $0,72^{\mathrm{dB}}$ & $0,84^{\mathrm{cB}}$ & $0,99^{\mathrm{bB}}$ & $1,11^{\mathrm{bB}}$ & $1,25^{\mathrm{aB}}$ & $1,34^{\mathrm{aB}}$ & $1,44^{\mathrm{aB}}$ & 0,74 \\
\hline $\mathrm{x}$ & 0,11 & 0,18 & 0,24 & 0,33 & 0,42 & 0,54 & 0,67 & 0,80 & 0,94 & 1,05 & 1,16 & 1,27 & 1,35 & \\
\hline
\end{tabular}

Letras iguais minúsculas na mesma linha e maiúsculas na mesma coluna não diferem entre si em nível de 5\% de significância pelo teste de Scott-Knott. 
Conforme observado na Tabela 4, a marca F, após duas horas em maceração, apresentou maior absorbância que as demais, indicando maior perda de solúveis, o que pode estar relacionado ao maior envelhecimento do grão em relação aos demais. Além disso, houve aumento da absorbância do caldo com o tempo de maceração, o que indicou a perda de solúveis. Romano et al. (2005), estudando o processo de hidratação dos grãos de feijão preto e carioca, encontraram porcentagem de sólidos solúveis superior a $2 \%$ no caldo de maceração do feijão hidratado por 16 horas. Para acelerar o processo de cocção do feijão, uma das práticas domésticas mais comuns é a maceração dos grãos. Porém, macro e micro nutrientes podem ser perdidos durante esse processo, bem como no processo de cozimento dos grãos (BARAMPAMA; SIMARD, 1995; RAMÍREZ-CÁRDENASI; LEONEL; COSTA, 2008).

Verificou-se (Tabela 5), para a água de maceração dos grãos do grupo preto, nos tempos de uma a cinco horas que não houve diferenças entre as marcas analisadas. Porém, nos tempos finais de maceração, as marcas $\mathrm{B}$ e $\mathrm{F}$ apresentaram os maiores valores de absorbância, indicando maior lixiviação de solúveis dos grãos, podendo ser consideradas de qualidade inferior às demais.

Não se observou relação entre a absorção de água e a perda de solúveis no caldo de maceração, uma vez que as marcas com maior perda de solúveis apresentaram boa absorção de água, podendo indicar que os grãos avaliados apresentavam boa qualidade, apesar das diferenças entre as marcas avaliadas.

$\mathrm{Na}$ Tabela 6 estão apresentadas as equações de regressão para cada marca das variedades do feijão carioca e preto e os coeficientes de determinação $\left(\mathrm{R}^{2}\right)$, obtidas a partir dos dados de absorbância do caldo de maceração. Assim como os dados de porcentagem de absorção de água, também o melhor ajuste obtido foi com equação logarítmica.

Tabela 6. Equações de regressão dos dados da porcentagem de absorção de água em grãos de feijão das variedades carioca e preto, macerados por uma hora em água a temperatura ambiente

\begin{tabular}{ccc}
\hline \multirow{2}{*}{ Marca } & \multicolumn{2}{c}{ Equações polinomiais para absorção de água } \\
\cline { 2 - 3 } & \multicolumn{1}{c}{ Carioca } & \multicolumn{1}{c}{ Preto } \\
\hline A & $\hat{y}=0,5425 \operatorname{Ln}(x)-0,066 R^{2}=0,99$ & $\hat{y}=0,4405 \operatorname{Ln}(x)-0,2628 R^{2}=0,86$ \\
$B$ & $\hat{y}=0,6084 \operatorname{Ln}(x)-0,1834 R^{2}=0,97$ & $\hat{y}=0,7921 \operatorname{Ln}(x)-0,5058 R^{2}=0,84$ \\
C & $\hat{y}=0,5968 \operatorname{Ln}(x)-0,1253 R^{2}=0,98$ & $\hat{y}=0,5007 \operatorname{Ln}(x)-0,3085 R^{2}=0,84$ \\
$D$ & $\hat{y}=0,5268 \operatorname{Ln}(x)-0,044 R^{2}=0,99$ & $\hat{y}=0,5299 \operatorname{Ln}(x)-0,3516 R^{2}=0,83$ \\
E & $\hat{y}=0,5923 \operatorname{Ln}(x)-0,0992 R^{2}=0,98$ & $\hat{y}=0,4695 \operatorname{Ln}(x)-0,2433 R^{2}=0,89$ \\
$F$ & $\hat{y}=0,7287 \operatorname{Ln}(x)-0,0549 R^{2}=0,98$ & $\hat{y}=0,5859 \operatorname{Ln}(x)-0,352 R^{2}=0,85$ \\
\hline
\end{tabular}

A maceração dos grãos com adição de água fervente é realizada com intuito de acelerar a absorção de água, facilitando assim o cozimento. A partir das equações obtidas com os grãos macerados em temperatura ambiente, para ambos parâmetros avaliados, foi realizada uma correlação entre a porcentagem de absorção de água e absorbância do caldo de maceração com água fervente e o tempo equivalente a temperatura ambiente. Os resultados desses valores estão apresentados na Tabela 7 . 
Tabela 7. Porcentagem de absorção de água e absorbância do caldo de maceração em grãos de feijão das variedades carioca e preto de diferentes marcas (M), macerados por uma hora em água fervente e o tempo equivalente em maceração a temperatura ambiente

\begin{tabular}{ccccccccc}
\hline M & \multicolumn{2}{c}{$\begin{array}{c}\text { Porcentagem de } \\
\text { absorção de água }\end{array}$} & $\begin{array}{c}\text { Tempo equivalente a absorção } \\
\text { de água em T } \begin{array}{c}\text { ambiente } \\
\text { (horas) }\end{array}\end{array}$ & Absorbância* & \multicolumn{2}{c}{$\begin{array}{c}\text { Tempo equivalente a } \\
\text { absorbância em T } \\
\text { (horas) ambiente }\end{array}$} \\
\cline { 2 - 9 } & Carioca & Preto & Carioca & Preto & Carioca & Preto & Carioca & Preto \\
\hline A & 81,42 & 82,53 & 7,95 & 8,46 & 1,89 & 1,38 & 36,8 & 41,65 \\
B & 79,95 & 81,01 & 8,94 & 9,46 & 1,73 & 1,97 & 23,3 & 22,77 \\
C & 78,65 & 80,89 & 6,64 & 8,56 & 2,03 & 1,87 & 37,16 & 77,55 \\
D & 77,88 & 80,74 & 8,03 & 8,56 & 2,00 & 2,14 & 48,7 & 110,1 \\
E & 76,29 & 80,08 & 6,60 & 8,08 & 1,92 & 1,71 & 30,34 & 64,10 \\
F & 75,24 & 79,34 & 5,50 & 7,34 & 2,22 & 1,75 & 22,93 & 36,15 \\
\hline $\mathrm{x}$ & 78,24 & 80,87 & 7,28 & 8,41 & 1,97 & 1,80 & 33,21 & 58,73 \\
\hline
\end{tabular}

*absorbância medida a $352 \mathrm{~nm}$ para o feijão carioca e $570 \mathrm{~nm}$ para o feijão preto.

Observou-se comportamento diferente para as variáveis analisadas quando se utilizou a maceração com adição de água fervente. A porcentagem de absorção de água dos grãos macerados com água em ebulição foi inferior ao obtido após $13 \mathrm{~h}$ de maceração em água à temperatura ambiente e, para ambas as variedades analisadas, este valor representou, no máximo, aproximadamente $9,5 \mathrm{~h}$ de maceração em temperatura ambiente, não sendo possível alcançar a hidratação máxima dos grãos por este processo. Por outro lado, a utilização da prática de maceração com adição de água fervente aumenta muito a extração de solúveis, o que pode ser observado pela equivalência de até $110 \mathrm{~h}$ de maceração a temperatura ambiente, em relação a uma marca de feijão preto. Apesar dessa prática poder acarretar a retirada maior de fatores antinutricionais presentes no grãos, o aumento da absorbância do caldo, quando se utiliza água em ebulição pode acarretar prejuízos na cor no produto final e mesmo perda de nutrientes importantes (OLIVEIRA et al., 2001; ROMANO et al., 2005).

Para Evangelista e Regitano-D’Arce (1997), os sólidos solúveis são lixiviados dos grãos de soja em velocidades relativamente constantes durante toda a hidratação e as quantidades lixiviadas são maiores em temperaturas mais elevadas. A temperatura é o fator mais importante na absorção de água e perda de sólidos.

Na Tabela 8 são apresentados os valores de $\mathrm{pH}$ dos grãos inteiros de feijão das variedades preto e carioca.

Segundo Liu, McWatters e Phillips (1992), as condições inadequadas de armazenamento podem levar à acidificação do tecido devido a hidrólise enzimática de lipídios em ácidos graxos, oxidação desses ácidos em ácidos orgânicos, hidrólise de proteínas pelas proteases com aumento de aminoácidos, o que conduz à instalação do defeito HTC. 
Tabela 8. Valores de pH dos grãos inteiros de seis marcas de feijão das variedades carioca e preto

\begin{tabular}{ccc}
\hline \multirow{2}{*}{ Marca } & \multicolumn{2}{c}{$\mathrm{pH}$} \\
\cline { 2 - 3 } & Carioca & Preto \\
\hline $\mathrm{A}$ & $6,44 \mathrm{~A}$ & $6,36 \mathrm{~A}$ \\
$\mathrm{~B}$ & $6,43 \mathrm{~A}$ & $6,32 \mathrm{~A}$ \\
$\mathrm{C}$ & $6,39 \mathrm{AB}$ & $6,30 \mathrm{~A}$ \\
$\mathrm{D}$ & $6,34 \mathrm{BC}$ & $6,34 \mathrm{~A}$ \\
$\mathrm{E}$ & $6,34 \mathrm{BC}$ & $6,33 \mathrm{~A}$ \\
$\mathrm{~F}$ & $6,30 \mathrm{C}$ & $6,17 \mathrm{~B}$ \\
\hline média & 6,37 & 6,30 \\
\hline CV(\%) & 0,48 & 0,37 \\
Fcal & $10,27 * *$ & $26,01 * *$ \\
DMS & 0,0843 & 0,0646 \\
\hline
\end{tabular}

Letras iguais maiúsculas na mesma coluna, não diferem entre si em nível de $5 \%$ de significância.

$* *=$ significativo a $1 \%$.

Observa-se, para os grãos do grupo cores, variedade carioca, diferenças nos valores de $\mathrm{pH}$ das marcas analisadas, sendo a marca $\mathrm{F}$ a que apresentou menor pH, e também apresentou maior lixiviação de sólidos solúveis para o caldo de maceração. Nos grãos da variedade preto, também a marca $\mathrm{F}$ apresentou menor valor de $\mathrm{pH}$ e maiores valores de absorbância, podendo haver relação entre esses dois parâmetros. Liu, McWatters e Phillips (1992) e Martin-Cabrejas et al. (2004) e Coelho (2004) sugeriram que o pH poderia ser indicador conveniente do defeito HTC em grãos de feijão, uma vez que encontraram interações significativas entre a acidificação do tecido ocorrida durante a estocagem e o aumento da dureza do grãos. No presente trabalho não se pode afirmar se os grãos apresentavam o defeito HTC, uma vez que não houve controle do tempo de armazenamento das amostras avaliadas. Porém, observou-se diferença significativa do $\mathrm{pH}$ medido, o que indica acidificação em diferentes graus, que pode ser indicativo de tempo de armazenagem diferente das amostras avaliadas.

\section{Conclusões}

As marcas comerciais de feijão disponíveis no comércio da cidade de Cascavel - PR apresentaram diferenças na absorção de água, absorção de luz do caldo e $\mathrm{pH}$, indicando que a qualidade tecnológica dos grãos de feijão varia de acordo com a marca e que as mesmas podem se encontrar em diferentes estágios de armazenamento. A maceração dos grãos com adição de água em ebulição aumenta a perda de sólidos solúveis dos grãos.

\section{Referências}

ABREU, C. M. P. ; CORRÊA, A. D.; ESTEVES, A. M.; SANTOS, C. D. Comparação química e enzimática de seis linhagens de feijão (Phaseolus vulgaris L.). Ciência e Agrotecnologia, Lavras, v. 26, n. 5, p. 999-1005, set./ out. 2002.

ABU-GHANNAM, N. Interpretation of the force deformation curves of soaked red Kidney beans (Phaseolus vulgaris L.). International Journal of Food Science and Technology, London, v. 33, n. 6, p. 509-515, 1998.

BARAMPAMA, Z.; SIMARD, R. E. Effects of soaking, cooking and fermentation on composition, in-vitro starch digestibility and nutritive value of common beans. Plant Foods for Human Nutrition, Amsterdam, v. 48, n. 4, p. 349-365, 1995.

BASSINELLO, P. Z.; CASTRO, M. G.; OLIVEIRA, L. L. R.; SOARES, D. M.; PELOSO, M. J.; SILVA C. C.; THUNG, M. Decoada e outros químicos para reduzir o tempo de cocção e seus efeitos na qualidade culinária de feijão. In: CONGRESSO NACIONAL DE PESQUISA DE FEIJÃO, 8., 2005, Goiânia. Anais... Santo Antônio de Goiás: Embrapa Arroz e Feijão, 2005. v. 2. p. 691-694. 
BRAGANTINI, C. Alguns aspectos do armazenamento de sementes e grãos de feijão. Santo Antônio de Goiás: Embrapa Arroz e Feijão, 2005.

CASTELLANOS, J. Z.; MALDONADO, H. G.; JIMÉNEZ, A. Hábitos preferenciales de los consumidores de frijol común (Phaseolus vulgaris, L.) en México. Archivos Latinoamericanos de Nutricion, Caracas, v. 47, n. 2, p. 163-167, 1997.

COELHO, S. R. M. Fenômeno HTC em feijão comum (Phaseolus vulgaris L.): Alterações quimicas, físicoquimicas e fisicas durante envelhecimento natural $e$ acelerado. 2004. Tese (Doutorado em Ciência de Alimentos) - Universidade Estadual de Londrina, Londrina.

COSTA, G. R.; RAMALHO, M. A. P.; ABREU, A. F. B. Variabilidade para a absorção de água nos grãos de feijão do Germoplasma da UFLA. Ciência e Agrotecnologia, Lavras, v. 25, n. 4, p. 1017-1021, jul./ago. 2001.

EVANGELISTA, C. M.; REGITANO-D'ARCE, M. A. B. Análise espectrofotométrica da ação das lipoxigenases em grãos de soja macerados em diferentes temperaturas. Ciência e Tecnologia de Alimentos, Campinas, v. 17, n. 3, p. 270-274, 1997.

INSTITUTO BRASILEIRO DE GEOGRAFIA E ESTATÍSTICA - IBGE. Indicadores IBGE estatística da produção agrícola junho de 2007. Disponível em: <www. ibge.gov.br/home/estatistica/indicadores/agropecuaria/ 1spa/default.shtm>. Disponível em: 13 ago. 2007.

LIU, K. Cellular, biological, and physicochemical basis for the hard-to-cook defect in legume seeds. Critical Reviews in Food Science and Nutrition, Boca Raton, v. 35, n. 4, p. 263-298, 1995.

LIU, K.; MCWATTERS, K. H.; PHILLIPS, R. D. Protein Insolubilization and thermal destabilization during storage as related to hard-to-cook defect in cowpeas. Journal of the Science of Food and Agriculture, Easton, v. 40, n. 12, p. 2483-2487, 1992.

MARTIN-CABREJAS, M. A; ADRIA, B. S.; MOLLÁ, S.; ESTEBAN, R.;LÓPEZ-ANDRÉU, F. J. Effect of fermentation and autoclaving on dietary fiber fractions and antinutritional factors of beans (Phaseolus vulgaris L.). Journal of Agriculture and Food Chemistry, Washington, v. 52, n. 20, p. 261-266, 2004.
MAURER, G.A.; OZEN, B. F.; MAUER, L. J.; NIELSEN, S. S. Analysis of hard-to-cook red and black common beans using fourier transform infrared spectroscopy. Journal of Agriculture and Food Chemistry, Washington, v. 52, n. 6, p. 1470-1477, 2004.

OLIVEIRA, A. C., QUEIROZ, K. S.; HELBIG, E.; REIS, S. M. P. M.; CARRARO, F. O processamento doméstico do feijão-comum ocasionou uma redução nos fatores antinutricionais fitatos e taninos, no teor de amido e em fatores de flatulência rafinose, estaquiose e verbascose. Archivos Latinoamericanos de Nutrição, Caracas, v. 51, n. 3, p. 276-283, 2001.

RAMIREZ-CARDENASI, L.; LEONEL, A. J.; COSTA, N. M. B. Efeito do processamento doméstico sobre o teor de nutrientes e de fatores antinutricionais de diferentes cultivares de feijão comum. Ciência e Tecnologia de Alimentos, Campinas, v. 28, n. 1, p. 200-213, 2008

RAMOS JUNIOR, E. U.; LEMOS, L. B.; SILVA, T. R. B. Componentes da produção, produtividade de grãos e características tecnológicas de cultivares de feijão. Bragantia, Campinas, v. 64, n. 1, p. 75-82, 2005.

REYES-MORENO, C.; PAREDES-LOPEZ, O. Hard-tocook phenomenon in common beans - a review. Critical Reviews in Food Science and Nutrition, Boca Raton, v. 33, n. 3. p. 227-286, 1993.

ROMANO, C. R.; HELBIG, E; RUTZ, D.; ELIAS, C. C. Avaliação de sólidos totais e proteína solúvel na água de hidratação de feijões (Phaselus vulgaris L.). In: CONGRESSO NACIONAL DE PESQUISA DE FEIJÃO, 8., 2005, Goiânia. Anais... Santo Antônio de Goiás: Embrapa Arroz e Feijão, 2005. v. 2. p. 684-686.

SANTOS, C. M. R.; MENEZES, N. L.; VILLELA, F. A. Modificações fisiológicas e bioquímicas em sementes de feijão no armazenamento. Revista Brasileira de Sementes, Pelotas, v. 27, n. 1, p. 104-114, 2005.

UNIVERSIDADE ESTADUAL PAULISTA - UNESP. Sistema para análises estatísticas. ESTAT v. 2.0. Jaboticabal: UNESP, 1991.

YOKOYAMA, L. P. Importância econômica. Embrapa Arroz e Feijão. Sistemas de Produção. Disponível em: $\quad<$ http://sistemasdeproducao.cnptia.embrapa.br/ FontesHTML/Feijao/CultivodoFeijoeiro/importancia. $\mathrm{htm}>$. Acesso em: 10 ago. 2006. 